\title{
Predicting fiber composite damage and failure
}

\section{Klaus Rohwer}

\begin{abstract}
Considerable effort has been put into the development of models describing damage and failure of fiber composites. This paper aims at providing an overview of models for intralaminate fracture of continuous fiber-reinforced polymer composites under quasi-static load. The models are grouped into homogeneous ones, those with some effect of inhomogeneity between fibers and the matrix, and fully inhomogeneous ones. Even a world-wide competition was not able to decide for the one and only homogeneous model. Accounting for the inhomogeneity between fibers and the matrix allows being more close to the real behavior on the account of higher computational effort. They suffer, however, from the difficulty to gather reliable material data. In summary, it must be concluded that a fully satisfying solution is not yet available. Consequently, for the time being, a real test remains the authentic way to secure structural strength.
\end{abstract}

\section{Keywords}

Polymer-matrix composites, unidirectional laminate, intralaminar strength, modeling, failure criteria

\section{Introduction}

For an efficient design the structural engineer needs to know as accurately as possible under what conditions the designated material will develop damage and finally will fail. Only then he is able to fully exploit the potential of the structure and to keep the required safety. In any case, some information on damage and failure must be obtained by suitable tests. These tests are usually performed on coupons and aimed at determining the material strength under a specific single state of stress, be it pure tension, compression or shear. The general state of stress in a loaded structure, however, consists of several, if not all, components of the stress tensor. Thus, a criterion is needed which maps the actual state of stress to the limited number of test results.

This paper is not intended to develop a new model for predicting fiber composites damage and failure. Rather it will review the different possibilities of formulating criteria and point out development tendencies, limited to laminated continuous fiber-reinforced polymer composites. Such reviews have been performed previously, for instance by Nahas ${ }^{1}$ or Thom. ${ }^{2}$ Since then, however, models have been developed further. In parts that is due to the tremendous increase in computational power which allows for more and more complex models. Besides, the World-Wide Failure Exercises (WWFE), WWFE-I, $^{3}$-II, ${ }^{4}$ and - III $^{5}$ have demonstrated deficiencies in the existing failure theories and therewith fired new developments. The large number of existing theories prohibits recognizing them all; rather those will be valued which to the impression of the author has reached some level of acceptance. Furthermore, not every detail of the respective theory can be outlined; only those aspects will be referred which the author regards important.

The scope of this review is restricted to intralaminate fracture of laminates made from unidirectional (UD) layers which are subjected to quasi-static loading. That excludes delaminations, woven fabrics as well as effects resulting from fatigue or impact loads. Further, the material behavior after the first appearance of damage is of interest, especially for fiber composites. That is because in case of matrix failure the fibers often are able to carry much higher loads. Effects of the progressive failure of fiber composites have been extensively studied by Knight. ${ }^{6} \mathrm{He}$ differentiated between ply discounting approaches and continuum damage mechanics methods. Libonati and Vergani ${ }^{7}$

DLR, Institute of Composite Structures and Adaptive Systems, Braunschweig, Germany

\section{Corresponding author:}

Klaus Rohwer, DLR, Institute of Composite Structures and Adaptive Systems, Lilienthalplatz 7, 38108 Braunschweig, Germany.

Email: klaus.rohwer@dlr.de 
recently have tested fiber composite behavior before and after failure onset using thermography. They have identified three regions: an initial region without damage, a second region where micro-damages appear which may be initiated by pre-existing defects, and a third region with an extended damage size. Considering these results, within this paper the main focus is laid on the second and third region. Different failure criteria and damage progression models will be outlined, pros and cons be mentioned, and tendencies in the development will be identified.

A vast majority of existing failure criteria is formulated in stresses, and there are good arguments to do so. If in a thought experiment a rod with both ends fixed is subjected to a temperature decrease it would build up axial tensile stresses and finally fail, but the axial strains remain zero. If, contrariwise, the rod is simply supported and can expand freely no stresses would build up and the developing strains would not cause any failure hazard. Other arguments in favor of a formulation in stresses are given by Christensen. ${ }^{8}$ He mentioned that such a formulation would be more suitable in order to fit with fracture mechanics or dislocation dynamics. In addition, he pointed out that viscous material can fail under constant stress, but not under constant strain due to relaxation.

A major point of criticism against a stress-based criterion is related to strength measurements. Usually strength is obtained as the load carrying capacity at final failure. Many tests, however, show a rather nonlinear stress-strain behavior, which at least in parts is due to progressive damage. There is a need to clearly define failure of composites. From studies with crossply laminates, Sánchez-Heres et al. ${ }^{9}$ found out that an increased understanding is required regarding the effects of matrix cracks, and therefore the maximum allowable crack density, in order to reach a safer structure.

During the design phase "quick and dirty" methods are needed which are fast, simple to use, and lead into the right direction, but do not claim to be highly accurate. Among these is the netting theory, where only the fibers are accounted for carrying loads. Quite popular is a limitation of strains to a fixed amount. Further there is the $10 \%$ rule by Hart-Smith, ${ }^{10}$ predicting the strength and stiffness of fiber-polymer composites on the basis of simple rule-of mixtures. Though very useful, such methods will not be considered in the following.

\section{Homogeneous models}

\section{Homogeneous isotropic material}

A section on failure of homogeneous isotropic material may look somewhat displaced in a paper which aims at composites. However, micromechanical approaches look at the constituencies separately, and the matrix can be considered homogeneous and isotropic. In that respect it seems reasonable that the WWFE-II ${ }^{4}$ includes one test case with pure resin material. Kaddour and Hinton, ${ }^{11}$ however, stated that this test case was "aimed at assessing how the composite failure theories predict the compressive strength of an isotropic polymer material". Such a reason can at most be of minor relevance since composite failure theories are not intended to predict the strength of isotropic materials. That can be done better by well-established and validated models.

The development of failure criteria for homogeneous isotropic materials looks back to a long-ranging history, which is well documented by Christensen. ${ }^{12} \mathrm{He}$ especially valued the work of Coulomb and Mohr for brittle fracture as well as von Mises and Tresca for ductile behavior. Furthermore, Christensen ${ }^{13}$ developed a criterion valid for brittle as well as ductile behavior, where failure depends on the material properties but also on the imposed state of stress. An overview over models with relevance to resin failure was given by Fiedler et al. ${ }^{14}$ These authors have proven that the type of resin failure depends not only on the material itself, but also on the state of stress. They found out that "ductility is a function of the amount of tri-axiality and explains why ductile polymers behave brittle when used as a matrix in fiber reinforced composites". Such an effect was detected and analyzed already by Asp et al. ${ }^{15}$ Because of this behavior, properties determined from tests with neat resin must be handled with caution when used in a micromechanical failure analysis of fiber composites.

There is a general agreement that the failure envelope should be convex. Otherwise, unloading from a certain state of stress may indicate failure. It is under discussion, however, as to whether the failure surface should be open or closed. Christensen ${ }^{8}$ stated: "All historical efforts to derive general failure criteria used the condition that the isotropic material would not fail under compressive hydrostatic stress", which means that the failure surface is assumed open. In his treaties on failure surfaces for polymeric materials, Tschoegl ${ }^{16}$ pointed at "the common sense requirement that the surface should be open in the purely compressive octant (because hydrostatic compression at reasonable pressures cannot lead to failure in the ordinary sense)". For fiber composites the situation is different. Because of the stiff fibers an external hydrostatic load causes matrix stresses which differ considerably from hydrostatic ones. Comparing theories and experiments of the WWFE-II exercise, Kaddour and Hinton ${ }^{17}$ mentioned "the diversity exhibited between the theories as to whether certain failure envelopes are 'open' or 
"closed". However, this discrepancy should not exist, and Christensen ${ }^{8}$ has provided reasonable arguments why fiber composites cannot sustain unlimited hydrostatic pressure.

\section{Fiber composite}

Homogenization. By definition, fiber composites consist of at least two distinct phases with different properties: fibers and the matrix. In addition, a zone around the fibers with special properties can be identified as a third phase. Fibers are usually much stiffer than the matrix and thus carry the main load. Nevertheless, in many models the differences are smeared out since homogeneous models require less computational effort. The failure model development for homogenized composites is affected by those for homogeneous isotropic material.

Non-interactive criteria. The easiest criterion limits every stress component separately, not accounting for any interaction. Astonishingly enough this rather crude approach has been applied quite successfully by Zinoviev et al. ${ }^{18}$ in the first WWFE. The failure criterion was supplemented by a special model characterizing the progressive damage under transverse tension and in-plane shear of a UD ply within a multidirectional laminate. This model describes the loading as linear elastic - ideal plastic, and the unloading as linear elastic with a smaller module. A comparatively favorable performance was highlighted by Hinton et al. ${ }^{19}$ Some discrepancies between theoretical predictions and test results of Zinoviev et al. ${ }^{20}$ traced back to the assumption about the fatal impact of ultimate transverse compressive stresses in a single ply on the failure of the whole composite laminate.

Hart-Smith ${ }^{21-23}$ applied modified maximum strain as well as maximum stress criteria in the WWFE-I. The modification affects a truncation of the failure envelope in the biaxial tension-compression quadrant. Differences between analysis and test results are explained by deficiencies with respect to matrix-dominant failure. The maximum strain criterion in conjunction with plasticity used by Bogetti et al. ${ }^{24,25}$ delivered good results in the WWFE-I; the strengthening effect that appears under tri-axial loading or hydrostatic pressure, however, is obviously not well captured as has been admitted by Bogetti et al. ${ }^{26}$ Furthermore, Bogetti's theory predicts a completely closed failure envelope even for isotropic materials.

Nahas ${ }^{1}$ has referred to further non-interactive theories which to some degree account for the strength of the constituents. In general, however, these theories have not been used very often in practice. It is but the maximum strain model which because of its simplicity is still applied especially in the initial design phase.
Interpolation criteria. Following yield conditions for isotropic and orthotropic materials, Hoffman ${ }^{27}$ proposed a quadratic fracture condition accounting for the difference between tensile and compressive strength in fiber and transverse directions. Based on the idea that a tensor polynomial can describe the failure surface, Tsai and $\mathrm{Wu}^{28}$ came up with a similar approach. These popular failure criteria consider interactions between different components of the stress tensor. They suffer, however, from certain drawbacks. Distinguishing between fiber breakage, matrix cracks, or interface failure is not possible by a smooth mathematical function. Besides, determination of the interaction terms linked to the product of two normal stress components requires difficult tests under biaxial load; and these terms are important since they may indicate implausible strength levels above those in fiber direction. By comparing with test results under plain stress conditions Narayanaswami and Adelman ${ }^{29}$ concluded to rather set these terms to zero. Liu and $\mathrm{Tsai}^{30}$ underlined that the failure surface must be closed, and they gave an overview over different possibilities for the interaction terms. Further, they have outlined a procedure for determining progressive laminate failure using reduced moduli which in the end leads to last ply failure. DeTeresa and Larsen $^{31}$ have proposed relations between the interaction terms and the strengths in fiber and transverse direction which fit to an open failure surface. Test under hydrostatic pressure has shown no damage.

There are a number of other interpolation criteria with certain inconveniences or restrictions. The criterion proposed by Norris ${ }^{32}$ does not explicitly account for differences in tensile and compression strength; on application the user must check the sign of the different stress components and use corresponding strength values. The same holds for the Tsai-Hill criterion as described by Azzi and Tsai, ${ }^{33}$ which differs from the Norris criterion only in the interaction term of the axial and transverse normal stress. The proposal by Yamada and $\mathrm{Sun}^{34}$ is sometimes looked upon as a degeneration of the above mentioned criteria, a view which ignores the intention to determine the final failure of a laminate. Further, the shear strength to be used in this criterion must be determined in tests with crossply laminates leading to much higher values than that obtained from a single ply. It is also worth mentioning that Yamada and Sun stressed the need to account for statistical distributions of the strength values. The criterion by Rotem ${ }^{35,36}$ differentiates between failure in the fibers or in the matrix. Fiber failure $(\mathrm{FF})$ is modeled by a maximum stress criterion in fiber direction with some modifications accounting for effects of transverse stresses, whereas matrix failure is predicted using a quadratic interaction of axial, transverse, and shear 
stresses. By means of comparing with test results, Kaddour and Hinton ${ }^{17}$ stated that there are indications "that the theory does not discriminate adequately between initial and final failure".

Several other interpolation criteria have been mentioned by Nahas, ${ }^{1}$ which to the author's knowledge have not reached much public attention.

Physically based criteria. Distinguishing between interpolation criteria and physically based ones is somewhat artificial and a traditional classification. Neither are the interpolation criteria free of some physical background nor are the physically based ones free of some simple interpolation aspects. There rather is a gradual transition between both categories which makes it somewhat arbitrary where to draw the line.

In his model development, Hashin ${ }^{37}$ pointed out that using a formulation quadratic in stresses is based on curve fitting considerations rather than on physical reasoning. He looked at the stress invariants and differentiated between four failure modes: tension or compression in fiber or in transverse direction. For the inter-FF he followed the proposal by $\mathrm{Mohr}^{38}$ who exclusively held the stresses acting at the failure plane responsible. That implies to determine the most probable crack direction which is difficult to find analytically. For the quadratic formulation the general solution is not fully satisfying.

Building up on Hashin's model Puck ${ }^{39,40}$ formulated a criterion which yielded rather accurate results in the WWFE-I. He strictly distinguished between FF and IFF, where the latter comprises matrix cracks and fiber-matrix debonding. Puck, too, regarded the stresses in the fracture plain responsible for IFF. If the normal stress on the fracture plain is positive (tensile), then all three stress components foster the failure, whereas compressive stress increases the strength by means of internal friction. The different behavior under tension and compression requires additional material parameters which describe the inclination of the fracture master surface at zero normal stress. Recommendations for these inclination parameters are provided by Puck et al. ${ }^{41}$ Based on Puck's model the strength degradation of laminates which suffer from an IFF within a certain layer was investigated by Knops and Bögle. ${ }^{42}$ Also the German engineering guideline $^{43}$ regarding the analysis of components from fiber reinforced plastics relies on Puck's failure criterion. Dong et al. ${ }^{44}$ complemented Puck's theory by adding effects of ply thickness and ply angles of neighboring laminae.

The failure mode concept (FMC) as set up by Cuntze and Freund ${ }^{45}$ aimed at capturing the behavior of five different failure modes. Based on stress invariants the model provides one failure condition each for two FF modes and three IFF modes. Corresponding to Puck's inclination parameters two curve parameters are to be determined by multi-axial tests. Possible interactions between failure modes are accounted for by a probabilistically based series spring model approach. The FMC was subsequently improved by Cuntze. ${ }^{46,47}$ In connection with the behavior of isolated and embedded laminas special emphasis is put on the difference between the onset of failure and the final failure of composite laminates.

At NASA Langley Research Center, Dávila et al. ${ }^{48}$ have proposed failure criteria for fiber composite laminates under plane stress conditions which were extended to three-dimensional stress states by Pinho et al. $^{49}$ and eventually improved with respect to matrix compression failure by Pinho et al ${ }^{50}$ The failure model considers four different scenarios: tension in fiber and transverse direction as well as compression in fiber and transverse direction. For compression in fiber direction the effect of fiber undulation is regarded. Nali and Carrera $^{51}$ compared this approach against some interpolation criteria for plane-stress problems and found good agreement with test results.

In a detailed analysis Catalanotti et al. ${ }^{52}$ described certain pitfalls of existing 3D failure criteria. They pointed to the requirement of using in situ strength properties in order to account for the ply thickness effect. The pitfalls could be avoided by an improved criterion for transverse matrix failure. Longitudinal tension failure is predicted by a maximum strain criterion, and longitudinal compression failure accounts for fiber kinking. Building on this proposal and on the threedimensional plasticity model for composite laminates developed by Vogler et al. ${ }^{53}$ Camanho et al. ${ }^{54}$ formulated new criteria where transverse failure and kinking models are invariant-based. For validation in case of complex three-dimensional stress states computational micromechanics turned out to be a useful tool.

Damage mechanics approach. Damage mechanics uses internal variables to describe the progressive loss of rigidity due to damage of material rather than providing conditions at which a certain type of damage occurs. Ladevéze and Le Dantec ${ }^{55}$ have applied damage mechanics to set up a model which describes ply-wise matrix microcracking and fiber/matrix debonding, leading to a laminate failure criterion. This model was adopted by Payan and Hochard ${ }^{56}$ to study the behavior of UD laminates from carbon fiberreinforced plastics (CFRP) under shear and transverse tension. They found elastic behavior up to brittle failure in fiber direction, and gradient loss of rigidity due to damage under shear and transverse tension. Based on these results they developed a model which covers the damage state by means of two scalar-damage 
variables describing the loss of rigidity under shear and transverse tension loading, respectively. The model has proven to be valid for a "diffuse damage" phase where micro-cracks occur and it is limited to the first intralaminar macro-crack. Hochard et al. ${ }^{57}$ have further extended the model to problems with stress concentrations.

Barbero and de Vivo ${ }^{58}$ presented a damage mechanics approach where the damage surface has the shape of the Tsai-Wu ${ }^{28}$ criterion. But it goes beyond a failure criterion by "identifying a damage threshold, hardening parameters for the evolution of damage, and the critical values of damage". These parameters are all related to known material properties but not directly measurable (cf. Barbero and Cosso ${ }^{59}$ ).

Van Paepegem et al. ${ }^{60}$ performed tension tests with $[ \pm 45]_{2 \mathrm{~s}}$ laminates and used the results to determined one parameter each for shear modulus degradation and the accumulation of permanent shear strain. The same authors ${ }^{61}$ applied these parameters to a mesomechanical model which did not account for time-dependent effects like strain rate or viscoelasticity. Nevertheless they were able to describe the nonlinear behavior up to failure of glass-fiber reinforced composite laminates under various loads rather accurately. Time and temperature dependency of fracture strengths both in tension and compression were thoroughly studied by Miyano et al. ${ }^{62}$

A majority of models for damage progression in laminates are based on the unrealistic assumption that each ply behaves independently of its neighbors. In order to account for the interaction between adjacent layers Williams et al. ${ }^{63}$ developed a continuum damage approach for sub-laminates. Therewith it is not intended to predict details of damage at the ply level, rather to capture the sub-laminate's overall response. The idea was further upgraded by Forghani et al. ${ }^{64}$ considering several aspects specific for damage progression in multidirectional composite laminates and applied to the open hole problems of the WWFE-III. The open hole tension strength of composite laminates was also studied by Ridha et al. ${ }^{65}$ They found a significant interaction between delamination and in-plane damage, so that neglecting delamination would overestimate strength.

Frizzell et al. ${ }^{66}$ developed a numerical method based on continuum damage mechanics that is capable of describing sub-critical damage and catastrophic failure mechanisms in composite laminates. They proposed a "pseudo-current" damage evaluation approach which avoids convergence problems even for complex damage mechanisms.

\section{Models with some effect of inhomogeneity}

Fibers and the matrix material are characterized by a large disparity in stiffness and strength. Though smeared out in the models reviewed above it certainly influences the failure process and thus is reflected by certain features. In this section, approaches will be discussed which to some extent consider this influence but still show relations to the homogeneous models mentioned above.

This evidently holds for the discrete damage mechanics approach as proposed by Barbero and Cortes. ${ }^{67}$ By means of fracture mechanics applied to the inhomogeneous material they determined parameters for stiffness reduction of the homogenized structure. Barbero and $\operatorname{Cosso}^{59}$ showed that this approach can be successfully applied to model damage and failure of laminates from CFRP.

Inhomogeneity plays an important role in tests of inplane shear strength. There is as yet a deep disagreement as how to obtain reliable values. Odegard and Kumosa $^{68}$ have thoroughly investigated the standard Iosipescu test with $0^{\circ}$ specimens as well as the $10^{\circ}$ off-axis test. They found good agreement only if the Iosipescu tests are accompanied by fully nonlinear finite element analyses including plasticity and premature cracks, and the $10^{\circ}$ off-axis test must be carefully machined to avoid micro-crack at the specimen edges.

The growth of cracks in a UD fiber reinforced lamina was modeled by Cahill et al. ${ }^{69}$ By means of the extended finite element method (XFEM) for heterogeneous orthotropic materials where material interfaces are present as well as a modified maximum hoop stress criterion for determining the crack propagation direction at each step they found out that the crack will predominantly propagate along the fiber direction, regardless of the specimen geometry, loading conditions or presence of voids.

Matrix cracking and fiber-matrix debonding seem to impair each other. By means of shear load Nouri et al. ${ }^{70}$ generated fiber-matrix debonding and observed its effect on crack density under transverse load. The authors developed a modified transverse cracking toughness model.

In order to accomplish the tasks put forward in the WWFE-I, Gotsis et al. ${ }^{71}$ used the computer code ICAN by Murthy and Chamis, ${ }^{72}$ which determines material properties using micromechanics and accounts for laminate attributes like delamination or free edge effects. In addition to the maximum stress criterion a modified distortion energy failure criterion determines the ply failure. Comparison with the test results as provided by Gotsis et al. ${ }^{73}$ revealed reasonable results in cases of fiber dominated failure, but rather large discrepancies when matrix failure was predominant. Analysis methods were further improved to a full hierarchical damage tracking and applied in the WWFE-III challenge by Chamis et al. $^{74}$ Therewith constituent 
properties determined by inverse model application were used for the micromechanical analysis part.

\section{Inhomogeneous models}

Inhomogeneous models try to determine the strength limits from constituent properties. Some effort was put on the determination of tensile strength in fiber direction. Considering the standard composite design with an extension to failure of the matrix much higher than that of the fiber, the composite failure stress can be roughly estimated by the rule of mixture from the failure stress of the fiber and the matrix stress at fiber rupture. However, that does neither account for varying fiber strength along each single fiber nor for strength variation between fibers. A number of hypotheses accounting for these variations have been proposed, e.g. by Rosen $^{75}$ and Zweben, ${ }^{76}$ but the application is not very convincing. More recent developments along this line are the global load sharing scheme by Curtin, ${ }^{77}$ the simultaneous fiber-failure model by Koyanagi et al. ${ }^{78}$ and statistical models for fiber bundles in brittle-matrix composites by Lamon. ${ }^{79}$

Models for compressive strength in fiber direction were first set up by studying the buckling of fibers on an elastic support. Depending on the fiber volume fraction Dow and Rosen ${ }^{80}$ differentiated between an extension and a shear failure mode. Their results, however, proposed too high strength values. $\mathrm{Xu}$ and Reifsnider ${ }^{81}$ extended the model by assuming slippage between fibers and the matrix over certain regions and therewith determined a good agreement with test results. Following a thorough review of the models developed until then Lo and Chim ${ }^{82}$ proposed to improve the microbuckling concept by considering transverse isotropy of the fibers and the effects of resin Young's modulus, fiber misalignment, a weak fiber matrix interface as well as voids. They also pointed out that in case the strain to failure of the fibers is reached prior to buckling, then the compressive strength should be determined by the rule of mixture between fibers and the matrix. The effect of fiber misalignment and resultant kinking was studied by Budiansky and Fleck. ${ }^{83}$ Their model, however, was not able to predict the width of the kink band and its inclination. Micromechanical analyses of the kink band formation after fiber buckling including the effect of fiber misalignment were performed by Kyriakides et al. ${ }^{84}$ and by Jensen and Christoffersen. ${ }^{85}$ After a thorough derivation of a stress based model for fiber kinking, Ataabadi et al. ${ }^{86}$ pointed to certain drawbacks of the model. In order to alleviate them they proposed an improvement based on strains and used it to predict the compressive strength depending on the fiber misalignment. On validating this strain based model against test results Ataabadi et al ${ }^{87}$ found that for specimens with an off-axis angle $>0^{\circ}$ this model can predict the compressive strength of UD laminated composites with acceptable accuracy. Gutkin et al. ${ }^{88,89}$ distinguished between two different failure mechanisms: shear-driven fiber compressive failure and kinking/splitting. Similar to that approach Prabhakar and Waas ${ }^{90}$ studied the interaction of kinking and splitting by means of a 2D finite element model. With a perfect interface the stress-strain curve shows a typical instability behavior with a sharp peak and a snap-back branch afterwards. Since local strains then exceeded the strain to failure for polymer matrix material discrete cohesive zone elements were applied at the fiber-matrix interface. It turned out that it is important to know especially the mode-II cohesive strength of the interface in order to determine the compressive strength and failure mode of UD laminates accurately. The same authors ${ }^{91}$ further extended the micromechanical model of failure under compression to multidirectional laminates considering delaminations. That allowed studying the effect of stacking sequence on the compressive strength. Mishra and Naik ${ }^{92}$ used the inverse micromechanical method to calculate fiber properties and applied them to determine the compressive strength for a composite with a different fiber volume fraction. A formulation capable of obtaining the maximum compression stress, and the post-critical performance of the material once fiber buckling has taken place was proposed by Martinez and Oller. ${ }^{93}$ Dharan and Lin ${ }^{94}$ questioned the role of initial fiber waviness and kink band formation on the compressive strength in fiber direction. Like Lo and $\mathrm{Chim}^{82}$ did earlier, they rather extended the micro-buckling model of Dow and Rosen $^{80}$ by accounting for an interface layer around the fibers, the thickness and shear modulus of which have to be adjusted to test results. Zidek and Völlmecke ${ }^{95}$ used a simple analytical model introduced by Wadee et al. ${ }^{96}$ They improved it by accounting for initial fiber misalignment. Furthermore this model allows for predicting the kink band inclination angle.

Obviously, there is not a generally accepted opinion yet whether kink band formation is a failure mode that limits the compressive strength or rather a secondary effect which appears after buckling.

Tensile and compressive strength in transverse direction was studied by Asp et al. ${ }^{97,98}$ They used a micromechanical approach with a representative volume element, which thereafter became more and more popular. Not accounting for fiber-matrix debonding they have found that the fiber modulus has a significant effect on the failure caused by cavitation in the matrix. This brittle failure occurred earlier than yielding. A thin interphase of a rubbery material improves the transverse failure properties. Tensile and 
compressive strength with perfect fiber-matrix adhesion on the one hand and complete debonding on the other hand was compared by Carvelli and Corigliano. ${ }^{99}$ Assuming periodicity for rather small fiber volume fraction they determined finite strength under biaxial tension only with debonded interfaces. Transverse tensile failure behavior of fiber-epoxy systems was also studied by Cid Alfaro et al. ${ }^{100}$ They pointed at a strong influence of the relative strength of the fiber-epoxy interface and the matrix. Vaughan and McCarthy ${ }^{101}$ found out that in case of a strong fiber-matrix interface residual thermal stresses improve the transverse tensile strength.

Several authors also applied micromechanical means for analyzing fiber composite shear strength. King et al. ${ }^{102}$ determined the composite transverse shear strength, mainly to predict the effect of fiber surface treatment and sizing on the interfacial bond strength. They found out that the predicted composite shear strength strongly depends upon the type of matrix and the interface strength, and is not significantly dependent on the fiber properties. Axial tension tests on $\left[ \pm 45^{\circ}\right]_{\mathrm{s}}$ laminates are traditionally used to determine the composite shear stress-strain response. Comparing the shear behavior of CFRP with epoxy and PEEK matrix, Lafarie-Frenot and Touchard ${ }^{103}$ determined a pronounced plastic deformation but no visible damage in the low loading range. Higher load levels led to increased damage in the epoxy matrix and early failure whereas the PEEK material exhibited even larger plastic deformation in connection with a considerable change of the fiber angle. The detectability of microcracks, however, may have been limited due to the fact, that contrast agent for X-ray inspection was applied to the free edges only. In contrary, by means of tests with dog bone specimens and micromechanical analyses $\mathrm{Ng}$ et al. ${ }^{104}$ found out that it is micro-cracking rather than plasticity, which brings about the observed nonlinear softening. In V-notched rail shear tests on cross-ply laminates reinforced with HS fibers Totry et al. ${ }^{105}$ did not find any evidence of damage in the MTM57 epoxy resin after a shear deformation of $25 \%$. If the same resin was reinforced with HM fibers, however, intraply damage occurred at $\gamma_{12}=15 \%$. It seems rather unlikely that such large strains can appear without any damage. For laminates out of glass-fiber reinforced epoxy Giannadakis and Varna ${ }^{106}$ determined viscoelasticity and viscoplasticity as the major cause for nonlinearity, whereas the effect of microdamage is very small. Until verifying what really happens in the shear tests it seems to be unreasonable to invest further effort into modeling it.

Micromechanics were also used for strength prediction under combined loading. The influence of interface strength on the composite behavior under out-of-plane shear and transverse tension was studied by Canal et al. ${ }^{107}$ They concluded that homogeneous models like those proposed by Hashin or Puck cannot accurately predict the failure surface. Transverse compression and out-of-plane shear were analyzed by Totry et al., ${ }^{108}$ which led to the finding that interface decohesion must be taken into account for composites in matrix-dominated failure modes. Also for transverse compression and longitudinal shear Totry et al. ${ }^{109}$ discovered that the interface strength plays an important role for the composite strength. Ha et al. ${ }^{110}$ proposed a micromechanics based model which used the maximum stress criterion for FF, a modified von Mises yield criterion for matrix failure and a simple quadratic criterion for failure of the fiber-matrix interface. In order to simulate the tasks of the WWFE-II Huang et al. ${ }^{111}$ complemented these criteria with a progressive damage model taking care of the nonlinear matrix behavior. A damage factor of 0.4 was assumed for final rupture of the damaged material. Huang et al. ${ }^{112}$ further adapted the approach to the test results by using a quadratic FF criterion, a fiber kinking model, and a reduction of stress amplification factors for inplane shear terms. Melro et al. ${ }^{13,114}$ developed an elasto-plastic damage model suitable for epoxy matrix material which accounts for different behavior under transverse tension, transverse compression, and longitudinal as well as transverse shear.

\section{Conclusion and outlook}

Considerable effort has been put into the development of suitable models to reliably predict damage and failure of fiber composites. In spite of the inhomogeneity of the material homogeneous models were first choices for quite some time. They have developed from simple maximum stress or strain criteria via interpolation criteria to physically based ones. On looking at the frequency of publications in this field the development seems to have passed the top. There are quite a number of them available now. What is missing, however, is a reliable statement, which one should be applied in the respective case at hand.

Damage mechanics accounts for the residual strength after initial damage. In general that is done by stiffness reduction smearing out local effects and therewith simulating a material nonlinearity of the affected layer. There are indications that interactions between adjacent layers can have a considerable influence on the laminate strength, which also can be considered by means of damage mechanics models.

More close to the behavior of fiber composites are inhomogeneous models. The greater computational effort going along with such models is no longer a major handicap thanks to the rapid increase of 
computational power and storage capacity. It is more the difficulty to determine relevant material properties. That especially holds if the model considers an interface layer between fibers and the matrix. Inverse methods cannot be considered as the general solution to that problem since they require the choice of a micromechanical model in the first place. Compressive strength in fiber direction has attracted special attention. However, the role of kink band formation, which is observed in the failure process, seems to be not thoroughly understood.

All in all it must be concluded that models for predicting fiber composite damage and failure have not yet reached a fully satisfying state. For now and in the foreseeable future virtual testing of fiber composites can be suitably applied in the initial design phase and serve as a useful supplement during structural qualification. But models need further improvement before tests on real structures can be fully replaced by simulations.

\section{Conflict of interest}

None declared.

\section{Funding}

This research received no specific grant from any funding agency in the public, commercial, or not-for-profit sectors.

\section{References}

1. Nahas MN. Survey of failure and post-failure theories of laminated fiber-reinforced composites. J Compos Technol Res 1986; 8: 138-153.

2. Thom H. A review of the biaxial strength of fibre-reinforced plastics. Compos A 1998; 29A: 869-886.

3. Hinton MJ, Kaddour AS and Soden PD (eds). Failure criteria in fibre reinforced polymer composites: The World-Wide Failure Exercise. Oxford, UK: Elsevier Science Ltd, 2004.

4. Hinton MJ and Kaddour AS. The background to the second World-Wide Failure Exercise. J Compos Mater 2012; 46: 2283-2294.

5. Kaddour AS, Hinton MJ, Smith PA, et al. The background to the third world-wide failure exercise. J Compos Mater 2013; 47: 2417-2426.

6. Knight NF Jr. User-defined material model for progressive failure analysis. NASA CR-2006-214526, Washington DC, 2006.

7. Libonati F and Vergani L. Damage assessment of composite materials by means of thermographic analyses. Compos B 2013; 50: 82-90.

8. Christensen RM. http://www.failurecriteria.com (accessed 25 June 2013).

9. Sánchez-Heres LF, Ringsberg JW and Johnson E. Study on the possibility of increasing the maximum allowable stresses in fibre-reinforced plastics. J Compos Mater 2013; 47: 1931-1941.
10. Hart-Smith LJ. Expanding the capabilities of the TenPercent Rule for predicting the strength of fibre-polymer composites. Compos Sci Technol 2002; 62: 1515-1544.

11. Kaddour AS and Hinton MJ. Input data for test cases used in benchmarking triaxial failure theories of composites. J Compos Mater 2012; 46: 2295-2312.

12. Christensen RM. A comparative evaluation of three isotropic, two property failure theories. $J$ Appl Mech 2006; 73: 852-859.

13. Christensen RM. A comprehensive theory of yielding and failure for isotropic materials. J Eng Mater Technol 2007; 129: 173-181.

14. Fiedler B, Hojo M, Ochiai S, et al. Failure behavior of an epoxy matrix under different kinds of static loading. Compos Sci Technol 2001; 61: 1615-1624.

15. Asp LE, Berglund LA and Talreja R. A criterion for crack initiation in glassy polymers subjected to a composite-like stress state. Compos Sci Technol 1996; 56: 1291-1301.

16. Tschoegl NW. Failure surfaces in principle stress space. J Polym Sci C Polym Sympos 1971; 32: 239-267.

17. Kaddour AS and Hinton MJ. Maturity of 3D failure criteria for fibre-reinforced composites: comparison between theories and experiments: Part B of WWFE-II. J Compos Mater 2013; 47: 925-966.

18. Zinoviev PA, Grigoriev SV, Lebedeva OV, et al. The strength of multilayered composites under a plane-stress state. Compos Sci Technol 1998; 58: 1209-1223.

19. Hinton MJ, Kaddour AS and Soden PD. A further assessment of the predictive capabilities of current failure theories for composite laminates: comparison with experimental evidence. Compos Sci Technol 2004; 64: 549-588.

20. Zinoviev PA, Lebedeva OV and Tairova LP. A coupled analysis of experimental and theoretical results on the deformation and failure of composite laminates under a state of plane stress. Compos Sci Technol 2002; 62: 1711-1723.

21. Hart-Smith LJ. Predictions of the original and truncated maximum-strain failure models for certain fibrous composite laminates. Compos Sci Technol 1998; 58: 1151-1178.

22. Hart-Smith LJ. Predictions of a generalized maximumshear-stress failure criterion for certain fibrous composite laminates. Compos Sci Technol 1998; 58: 1179-1208.

23. Hart-Smith LJ. Comparison between theories and test data concerning the strength of various fibre-polymer composites. Compos Sci Technol 2002; 62: 1591-1618.

24. Bogetti TA, Hoppel CPR, Harik VM, et al. Predicting the nonlinear response and progressive failure of composite laminates. Compos Sci Technol 2004; 64: 329-342.

25. Bogetti TA, Hoppel CPR, Harik VM, et al. Predicting the nonlinear response and failure of composite laminates: correlation with experimental results. Compos Sci Technol 2004; 64: 477-485.

26. Bogetti TA, Staniszewski J, Burns BP, et al. Predicting the nonlinear response and progressive failure of composite laminates under triaxial loading: correlation with experimental results. J Compos Mater 2012; 47: 793-804. 
27. Hoffman O. The brittle strength of orthotropic materials. J Compos Mater 1967; 1: 200-206.

28. Tsai SW and Wu EM. A general theory of strength for anisotropic materials. J Compos Mater 1971; 5: 58-80.

29. Narayanaswami R and Adelman HM. Evaluation of the tensor polynomial and Hoffman strength theories for composite materials. J Compos Mater 1977; 11: 366-377.

30. Liu K-S and Tsai SW. A progressive quadratic failure criterion for a laminate. Compos Sci Technol 1998; 58: 1023-1032.

31. DeTeresa SJ and Larsen GJ. Reduction in the number of independent parameters for the Tsai-Wu tensor polynomial theory of strength for composite materials. J Compos Mater 2003; 37: 1769-1785.

32. Norris CB. Strength of orthotropic materials subjected to combined stresses. Forest Products Laboratory, Report 1816, May 1962, Madison, WI.

33. Azzi VD and Tsai SW. Anisotropic strength of composites. Exp Mech 1965; 5: 283-288.

34. Yamada SE and Sun CT. Analysis of laminate strength and its distribution. J Compos Mater 1978; 12: 275-284.

35. Rotem A. Prediction of laminate failure with the Rotem failure criterion. Compos Sci Technol 1998; 58: 1083-1094.

36. Rotem A. The Rotem failure criterion for fibrous laminated composite materials: three-dimensional loading case. J Compos Mater 2012; 46: 2379-2388.

37. Hashin Z. Failure criteria for unidirectional fiber composites. J Appl Mech 1980; 47: 329-334.

38. Mohr O. Welche Umstände bedingen die Elastizitätsgrenze und den Bruch eines Materials? Zeitschrift des Vereins Deutscher Ingenieure 1900; 24: 1524-1530, 1572-1577.

39. Puck A. Festigkeitsanalyse von Faser-Matrix-Laminaten: Modelle für die Praxis. München, Wien: Hanser, 1996.

40. Puck A and Schürmann H. Failure analysis of FRP laminates by means of physically based phenomenological models. Compos Sci Technol 1998; 58: 1045-1067.

41. Puck A, Kopp J and Knops M. Guidelines for the determination of the parameters in Puck's action plane strength criterion. Compos Sci Technol 2002; 62: 371-378.

42. Knops M and Bögle C. Gradual failure in fibre/polymer laminates. Compos Sci Technol 2006; 66: 616-625.

43. Anonymus. Development of FRP components (fibre-reinforced plastics) analysis, Part 3. Berlin: Beuth Verlag, 2006.

44. Dong H, Wang $J$ and Karihaloo BL. An improved Puck's failure theory for fibre-reinforced composite laminates including the in situ strength effect. Compos Sci Technol 2014; 98: 86-92. http://dxdoi.org/10.1016/ j.compscitech.2014.04.009.

45. Cuntze R and Freund A. The predictive capability of failure mode concept-based strength criteria for multidirectional laminates. Compos Sci Technol 2004; 64: 343-377.

46. Cuntze R. Efficient 3D and 2D failure conditions for UD laminae and their application within the verification of the laminate design. Compos Sci Technol 2006; 66: 1081-1096.
47. Cuntze R. The predictive capability of failure mode concept-based strength conditions for laminates composed of unidirectional laminae under static triaxial stress states. J Compos Mater 2012; 46: 2563-2594.

48. Dávila CG, Camanho PP and Rose CA. Failure criteria for FRP laminates. J Compos Mater 2005; 39(4): 323-345.

49. Pinho ST, Dávila CG, Camanho PP, et al. Failure models and criteria for FRP under in-plane or three-dimensional stress states including shear non-linearity. NASA/TM2005-213530, 2005, Hampton, VA 23681.

50. Pinho ST, Iannucci L and Robinson P. Physically-based failure models and criteria for laminated fibre-reinforced composites with emphasis on fibre kinking: Part I: development. Compos A 2006; 37: 63-73.

51. Nali P and Carrera E. A numerical assessment on twodimensional failure criteria for composite layered structures. Compos B 2012; 43: 280-289.

52. Catalanotti G, Camanho PP and Marques AT. Threedimensional failure criteria for fiber-reinforced laminates. Compos Struct 2013; 95: 63-79.

53. Vogler M, Rolfes R and Camanho PP. Modeling the inelastic deformation and fracture of polymer composites - Part I: plasticity model. Mech Mater 2013; 59: 50-64.

54. Camanho PP, Arteiro A, Melro AR, et al. Three-dimensional invariant-based failure criteria for fibre-reinforced composites. Int J Solids Struct. Epub ahead of print 2014. DOI: http://dx.doi.org/10.1016/j.ijsolstr.2014.03.038.

55. Ladevèze $\mathrm{P}$ and Le Dantec E. Damage modelling of the elementary ply for laminated composites. Compos Sci Technol 1992; 43: 257-267.

56. Payan J and Hochard C. Damage modelling of laminated carbon/epoxy composites under static and fatigue loadings. Int J Fatigue 2002; 24: 299-306.

57. Hochard C, Moit S and Thollon Y. Fatigue of laminated composite structures with stress concentrations. Compos B. Epub ahead of print 2013. http://dx.doi.org/ 10.1016/j.compositesb.2013.10.020.

58. Barbero EJ and de Vivo L. A constitutive model for elastic damage in fiber-reinforced PMC laminae. Int $J$ Damage Mech 2001; 10: 73-93.

59. Barbero EJ and Cosso FA. Determination of material parameters for discrete damage mechanics analysis of carbon-epoxy laminates. Compos B 2014; 56: 638-646.

60. Van Paepegem W, De Baere I and Degrieck J. Modelling the nonlinear shear stress-strain response of glass fibrereinforced composites. Part I: experimental results. Compos Sci Technol 2006; 66: 1455-1464.

61. Van Paepegem W, De Baere I and Degrieck J. Modelling the nonlinear shear stress-strain response of glass fibrereinforced composites. Part II: model development and finite element simulations. Compos Sci Technol 2006; 66: 1465-1478.

62. Miyano Y, Kanemitsu M, Kunio T, et al. Role of matrix resin on fracture strengths of unidirectional CFRP. J Compos Mater 1986; 20: 520-538.

63. Williams KV, Vaziri R and Poursartip A. A physically based continuum damage mechanics model for thin laminated composite structures. Int J Solids Struct 2003; 40: 2267-2300. 
64. Forghani A, Zobeiry N, Poursartip A, et al. A structural modelling framework for prediction of damage development and failure of composite laminates. J Compos Mater 2013; 47: 2553-2573.

65. Ridha M, Wang $\mathrm{CH}$, Chen BY, et al. Modelling complex progressive failure in notched composite laminates with varying sizes and stacking sequences. Compos $A$ 2014; 58: $16-23$.

66. Frizzell RM, McCarthy MA and McCarthy CT. Numerical method to control high levels of damage growth using an implicit finite element solver applied to notched cross-ply laminates. Compos Struct 2014; 110 : 51-61.

67. Barbero EJ and Cortes DH. A mechanistic model for transverse damage initiation, evolution, and stiffness reduction in laminated composites. Compos B 2010; 41: 124-132.

68. Odegard $G$ and Kumosa M. Determination of shear strength of unidirectional composite materials with the Iosipescu and $10^{\circ}$ off-axis shear tests. Compos Sci Technol 2000; 60: 2917-2943.

69. Cahill LMA, Natarajan S, Bordas SPA, et al. An experimental/numerical investigation into the main driving force for crack propagation in uni-directional fibre-reinforced composite laminae. Compos Struct 2014; 107: 119-130.

70. Nouri H, Lubineau G and Traudes D. An experimental investigation of the effect of shear-induced diffuse damage on transverse cracking in carbon-fiber reinforced laminates. Compos Struct 2013; 106: 529-536.

71. Gotsis PK, Chamis CC and Minnetyan L. Prediction of composite laminate fracture: micromechanics and progressive fracture. Compos Sci Technol 1998; 58: 1137-1149.

72. Murthy PLN and Chamis CC. Integrated composite analyzer (ICAN), Users and Programmers Manual. NASA Technical Paper 2515, Lewis Research center, Cleveland, OH, 1986.

73. Gotsis PK, Chamis CC and Minnetyan L. Application of progressive fracture analysis for predicting failure envelopes and stress-strain behaviors of composite laminates: a comparison with experimental results. Compos Sci Technol 2002; 62: 1545-1559.

74. Chamis CC, Abdi F, Garg M, et al. Micromechanicsbased progressive failure analysis prediction for WWFE-III composite coupon test cases. J Compos Mater 2013; 47: 2695-2712.

75. Rosen BW. Tensile failure of fibrous composites. AIAA J 1964; 2(11): 1985-1991.

76. Zweben C. A bounding approach to the strength of composite materials. Eng Fracture Mech 1972; 4: 1-8.

77. Curtin WA. Theory of mechanical properties of ceramicmatrix composites. J Am Ceram Soc 1991; 74: 2837-2845.

78. Koyanagi J, Hatta H, Kotani M, et al. A comprehensive model for determining tensile strengths of various unidirectional composites. J Compos Mater 2009; 43: 1901-1914.

79. Lamon J. Stochastic models of fragmentation of brittle fibers or matrix in composites. Compos Sci Technol 2010; 70: 743-751.
80. Dow NF and Rosen BW. Evaluations of filament-reinforced composites for aerospace structural applications. Washington DC: NASA CR-207, 1965.

81. Xu YL and Reifsnider KL. Micromechanical modeling of composite compressive strength. J Compos Mater 1993; 27: $572-588$.

82. Lo KH and Chim ES-M. Compressive strength of unidirectional composites. J Reinf Plast Compos 1992; 11 : 383-396.

83. Budiansky B and Fleck N. Compressive failure of fiber composites. J Mech Phys Solids 1993; 41: 183-211.

84. Kyriakides S, Arseculeratne R, Perry EJ, et al. On the compressive failure of fiber reinforced composites. Int $J$ Solids Struct 1995; 32: 689-738.

85. Jensen HM and Christoffersen J. Kink band formation in fiber reinforced materials. J Mech Phys Solids 1997; 45: 1121-1136.

86. Ataabadi AK, Ziari-Rad S and Hosseini-Toudeshky H. An improved model for fiber kinking analysis of unidirectional laminated composites. Appl Compos Mater 2011; 18: 175-196.

87. Ataabadi AK, Hosseini-Toudeshky $\mathrm{H}$, et al. Experimental and analytical study on fiber-kinking failure mode of laminated composites. Compos B 2014; 61: 84-93.

88. Gutkin R, Pinho ST, Robinson P, et al. Micro-mechanical modelling of shear-driven fibre compressive failure and of fibre kinking for failure envelope generation in CFRP laminates. Compos Sci Technol 2010; 70: 1214-1222.

89. Gutkin R, Pinho ST, Robinson P, et al. On the transition from shear-driven fibre compressive failure to fibre kinking in notched CFRP laminates under longitudinal compression. Compos Sci Technol 2010; 70: 1223-1231.

90. Prabhakar P and Waas AM. Interaction between kinking and splitting in the compressive failure of unidirectional fiber reinforced laminated composites. Compos Struct 2013; 98: 85-92.

91. Prabhakar P and Waas AM. Micromechanical modeling to determine the compressive strength and failure mode interaction of multidirectional laminates. Compos A 2013; 50: $11-21$.

92. Mishra A and Naik NK. Inverse micromechanical models for compressive strength of unidirectional composites. J Compos Mater 2009; 43: 1199-1211.

93. Martinez X and Oller S. Numerical simulation of matrix reinforced composite materials subjected to compression loads. Arch Comput Methods Eng 2009; 16: 357-397.

94. Dharan CKH and Lin C-L. Longitudinal compressive strength of continuous fiber composites. J Compos Mater 2007; 41: 1389-1405.

95. Zidek RAE and Völlmecke C. Analytical studies on the imperfection sensitivity and on the kink band inclination angle of unidirectional fiber composites. Compos A. Epub ahead of print 2014. DOI: http://dx.doi.org/10.1016/ j.compositesa.2014.05.005.

96. Wadee MA, Völlmecke C, Haley JF, et al. Geometric modelling of kink banding in laminated structures. Philos Trans $R$ Soc A 2012; 370: 1827-1849. 
97. Asp LE, Berglund LA and Talreja R. Effect of fiber and interphase on matrix-initiated transverse failure in polymer composites. Compos Sci Technol 1996; 56: 651-665.

98. Asp LE, Berglund LA and Talreja R. Prediction of matrix-initiated transverse failure in polymer composites. Compos Sci Technol 1996; 56: 1089-1097.

99. Carvelli V and Corigliano A. Transverse resistance of long-fibre composites: influence of the fibre-matrix interface. In: Proceedings of the 11th European conference on composite materials ECCM11, Rhodes, Greece, May 31-June 3, 2004.

100. Cid Alfaro MV, Suiker ASJ and de Borst R. Transverse failure behavior of fiber-epoxy systems. J Compos Mater 2010; 44: 1493-1516.

101. Vaughan TJ and McCarthy CT. Micromechanical modelling of the transverse damage behaviour in fibre reinforced composites. Compos Sci Technol 2011; 71: 388-396.

102. King TR, Blackketter DM, Walrath DE, et al. Micromechanics prediction of the shear strength of carbon fiber/epoxy matrix composites: the influence of the matrix and interface strengths. $J$ Compos Mater 1992; 26: 558-573.

103. Lafarie-Frenot MC and Touchard F. Comparative inplane shear behavior of long-carbon-fibre composites with thermoset or thermoplastic matrix. Compos Sci Technol 1994; 52: 417-425.

104. Ng WH, Salvi AG and Waas AM. Characterization of the in-situ non-linear shear response of laminated fiberreinforced composites. Compos Sci Technol 2010; 70: 1126-1134.

105. Totry E, Molina-Aldareguía JM, González C, et al. Effect of fiber, matrix and interface properties on the in-plane shear deformation of carbon-fiber reinforced composites. Compos Sci Technol 2010; 70: 970-980.
106. Giannadakis K and Varna J. Analysis of non-linear shear stress-strain response of unidirectional GF/EP composite. Compos A. Epub ahead of print 2014. DOI: http://dx.doi.org/10.1016/j.compositesa.2014.03.009.

107. Canal LP, Segurado J and Llorca J. Failure surface of epoxy-modified fiber-reinforced composites under transverse tension and out-of-plane shear. Int $J$ Solids Struct 2009; 46: 2265-2274.

108. Totry E, González C and Llorca J. Failure locus of fiber-reinforced composites under transverse compression and out-of-plane shear. Compos Sci Technol 2008; 68: 829-839.

109. Totry E, González C and Llorca J. Prediction of the failure locus of C/PEEK composites under transverse compression and longitudinal shear through computational micromechanics. Compos Sci Technol 2008; 68: 3128-3136.

110. Ha SK, Jin KK and Huang Y. Micro-mechanics of failure (MMF) for continuous fiber reinforced composites. J Compos Mater 2008; 42: 1873-1895.

111. Huang Y, Xu L and Ha SK. Prediction of three-dimensional composite laminate response using micromechanics of failure. J Compos Mater 2012; 46: 2431-2442.

112. Huang Y, Jin C and Ha SK. Strength prediction of triaxially loaded composites using a progressive damage model based on micromechanics of failure. J Compos Mater 2013; 47: 777-792.

113. Melro AR, Camanho PP, Andrade Pires FM, et al. Micromechanical analysis of polymer composites reinforced by unidirectional fibres: Part I - constitutive modeling. Int J Solids Struct 2013; 50: 1897-1905.

114. Melro AR, Camanho PP, Andrade Pires FM, et al. Micromechanical analysis of polymer composites reinforced by unidirectional fibres: Part II - micromechanical analyses. Int J Solids Struct 2013; 50: 1906-1915. 